\title{
The effects of organic nitrates on osteoporosis: a randomized
} controlled trial [ISRCTN94484747]

\author{
Sophie A Jamal*1, Celeste J Hamilton ${ }^{1}$, Dennis Black² and \\ Steven R Cummings ${ }^{3}$
}

\begin{abstract}
Address: ${ }^{1}$ Department of Medicine, University of Toronto and Division of Endocrinology and Metabolism, St. Michael's Hospital, Toronto, Canada, ${ }^{2}$ Department of Epidemiology and Biostatistics, University of California, San Francisco, USA and ${ }^{3}$ California Pacific Medical Center Research Institute, San Francisco, USA
\end{abstract}

Email: Sophie A Jamal* - sophie.jamal@utoronto.ca; Celeste J Hamilton - hamiltonce@smh.toronto.on.ca; Dennis Black -dblack@psg.ucsf.edu; Steven R Cummings - scummings@psg.ucsf.edu

* Corresponding author

Published: 26 April 2006

Trials2006, 7:10 doi:10.1186/1745-62/5-7-10

This article is available from: http://www.trialsjournal.com/content/7/1/10

(c) 2006Jamal et al; licensee BioMed Central Ltd.

This is an Open Access article distributed under the terms of the Creative Commons Attribution License (http://creativecommons.org/licenses/by/2.0), which permits unrestricted use, distribution, and reproduction in any medium, provided the original work is properly cited.
Received: 21 March 2006

Accepted: 26 April 2006

\begin{abstract}
Background: Osteoporotic fractures are common and are associated with increased morbidity, mortality and health care costs. The most effective way to moderate increases in health care costs and the sickness and premature death associated with osteoporotic fractures, is to prevent osteoporosis. Several lines of evidence suggest that nitrates, drugs typically prescribed for the treatment of angina, may be effective in preventing postmenopausal osteoporosis.
\end{abstract}

Methods: We have designed a multicentre randomized controlled trial to determine the effects of nitrates on bone. The trial consists of two studies. The objective of the first study is to determine whether isosorbide mononitrate at $20 \mathrm{mg} /$ day or nitroglycerin ointment at $15 \mathrm{mg} /$ day leads to fewer headaches. The nitrate that is best tolerated will be used in a second study with one main objective: To determine if postmenopausal women with a T-score at the lumbar spine (LI to L4) between 0 and -2.0 randomized to two years of treatment with intermittent nitrates have a greater increase in spine bone mineral density as compared to women randomized to placebo.

We hypothesize that: I. Women will report fewer headaches when they are randomized to intermittent nitroglycerin ointment at $15 \mathrm{mg} /$ day compared to intermittent oral isosorbide mononitrate at $20 \mathrm{mg} / \mathrm{day}$, and, 2. After two years, women randomized to intermittent nitrates will have a greater percent increase in lumbar spine bone mineral density compared with women randomized to placebo.

Discussion: We have completed our pilot study and found that transdermal nitroglycerin was associated with fewer headaches than oral isosorbide mononitrate. We are currently recruiting patients for our second main study.

\section{I.0 Background}

\section{I.I The burden of illness due to osteoporosis}

Osteoporosis (OP) is characterized by a reduction in bone mass and disruption of skeletal microarchitecture leading to an increased susceptibility to fracture with minimal trauma. In Canada, one in four women have OP and in 


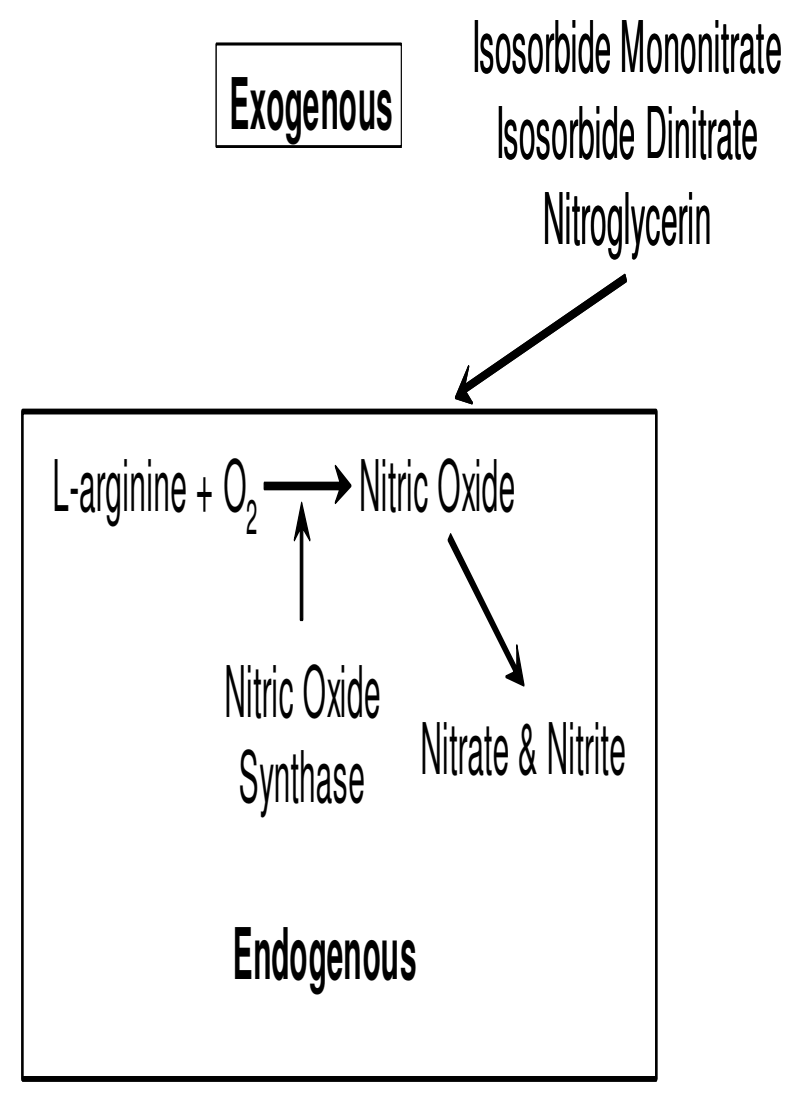

Figure I

Sources of nitric oxide.

1993 the total expenditure for fractures was in excess of 1.3 billion dollars $[1,2]$. The average length of stay in an acute care hospital after a hip fracture is three weeks; one of four patients must remain in long-term care institutions for at least one year; and one of three returns home but must depend on other people or devices for mobility. Furthermore, after a hip fracture there is up to a $20 \%$ increased risk of mortality [3].

As elderly men and women are the fastest growing group in the world and the incidence of OP fractures increases exponentially with age, the number of men and women with OP fractures is expected to increase dramatically over the next 50 years in Canada and world wide [3]. Assuming current demographic trends continue, the annual incidence of hip fractures worldwide could exceed 21 million in 2050 [4]. The most effective way to moderate increases in health care costs and the sickness and premature death associated with OP fractures, is to prevent OP.

Pharmacologic agents to prevent OP include estrogen replacement therapy (ERT), bisphosphonates (alendro- nate, risedronate, and etidronate), and selective estrogen receptor modulators (raloxifene). These medications decrease bone resorption. The resultant unopposed bone formation increases bone mineral density (BMD) and decreases fracture rates. Each medication has adverse effects, often resulting in discontinuation. For example, a randomized controlled trial (RCT) of the bisphosphonate alendronate reported that at 2 years, $60 \%$ of participants were adherent [5]. Bisphosphonates, if taken improperly, can cause gastrointestinal irritation and esophageal ulceration $[6,7]$. In addition, bisphosphonates cannot be prescribed for patients with impaired renal clearance, yet these patients are at particularly high risk for fractures [710].

Estrogen (with or without a progestin) reduces the risk of all types of fractures by $25-33 \%$ but with risks that outweigh its potential benefits for fractures in the vast majority of women [8]. Raloxifene is associated with a 3-fold increase in thromboembolic disease, an increase in hot flushes, leg cramps, leg swelling, and an influenza-like syndrome $[9,10]$.

Pharmacologic treatments are expensive: raloxifene and bisphosphonates cost $>\$ 700$ Canadian/year, are either unavailable or unaffordable outside of North America and Western Europe, and of uncertain safety when used long-term (> 10 years). The limitations of the current therapies have fuelled interest in alternatives. An optimal agent would be one that decreases bone resorption while also increasing bone formation to have maximal effects on BMD and ultimately fracture, is convenient to take, inexpensive, has minimal adverse effects, is safe for longterm use, and is available world wide. One potential agent is nitric oxide in the form of organic nitrate, the subject of this randomized trial.

This randomized trial consists of two studies. The objective of the first study is to determine whether isosorbide mononitrate (ISMO) at $20 \mathrm{mg} /$ day or nitroglycerin ointment (NTG) at $15 \mathrm{mg} /$ day results in fewer headaches. The nitrate that is best tolerated will be used in a second study with one main objective: To determine if postmenopausal women with a T-score at the lumbar spine (L1 to L4) between 0 and -2.0 randomized to two years of treatment with intermittent nitrates have a greater increase in spine $\mathrm{BMD}$ as compared to women randomized to placebo.

\section{I.2 Nitric oxide influences osteoclast and osteoblast activity}

Nitric oxide (NO) is a short-lived free radical involved in the regulation of many physiological processes, including bone remodeling $[11,12]$. There are three sources of NO (Figure 1). First, NO can be generated by nitric oxide synthase (NOS) from molecular oxygen and the terminal 
Table I: Effect of conjugated estrogen and transdermal nitroglycerin on BMD in ovariectomized rats 25.

\begin{tabular}{lc}
\hline Treatment group, $\mathrm{n}=5$ for all groups & Percent increase in BMD (L2-L4) over 6 weeks \\
\hline Sham operated & $25 \% \pm 2 \%$ \\
Ovariectomized rats & $8 \% \pm 3 \%$ \\
Ovariectomized + estrogen & $27 \% \pm 5 \% *$ \\
Ovariectomized + transdermal nitroglycerin & $20 \% \pm 3 \% \dagger$ \\
Ovariectomized + estrogen + nitroglycerin & $22 \% \pm 2 \% *$ \\
\hline
\end{tabular}

*Different than ovariectomized rats at $p<0.005$

$\dagger$ Different than ovariectomized rats at $p<0.02$

nitrogen of the amino acid L-arginine [12,13]. Second, NO can be generated nonenzymatically from nitrite in the acid environment of the stomach. Third, organic nitrates (e.g. nitroglycerin, isosorbide dinitrate, ISMO) can act as NO donors [14]. In vitro studies consistently demonstrate that NO has a biphasic effect on osteoclast activity and bone resorption [15-19]. Adding a NOS inhibitor to bone cell cultures results in low concentrations of $\mathrm{NO}$ and potentiates bone resorption. In contrast, adding NO to bone cell cultures results in high concentrations of $\mathrm{NO}$ and decreases osteoclast maturation and bone resorbing activity [20-23]. The effects of NO on osteoblasts and bone formation are less well characterized. Some, but not all, studies have found that low concentrations of NO stimulate osteoblast growth and differentiation and extremely high concentrations inhibit osteoblast growth and differentiation [24].

\section{I.3 The effect of nitric oxide on rodent bone}

NTG ointment, a NO donor, prevents bone loss in rats [25]. Ovariectomized rats were treated with vehicle, 17 beta estradiol, NTG ointment, or a combination of 17beta estradiol and NTG. Compared with baseline, treatment with NTG increased BMD in ovariectomized rats $(20 \% \pm 3 \%)$ to levels similar to those found in sham operated rats $(25 \% \pm 2 \%)$ and the increase in BMD in ovariectomized rats treated with NTG ointment $(20 \% \pm 3 \%)$ was greater than the increase in ovariectomized rats treated with vehicle $(8 \% \pm 3 \%)$ (Table 1$)$. This suggests that nitrates, which act as NO donors, might preserve or even increase bone mass.

\section{I.4 The effect of nitric oxide on bone - human studies}

In 1998, we began investigating the relationship between the use of nitrates and BMD in humans using data from the Study of Osteoporotic Fractures (SOF); a multicentre, prospective, observational study of 9704 ambulatory, Caucasian women, aged 65 years and older $[26,27]$. We hypothesized that women taking nitrates intermittently would have significantly higher bone mass than those who took nitrates continuously. Continuous exposure to organic nitrate causes tachyphylaxis to its vascular effects. Data from the cardiovascular literature report tachyphy- laxis to nitrates with increasing frequency of dose [28]. Tachyphylaxis to nitrates may develop in bone; rats given NTG ointment daily for 12 weeks had increases in BMD similar to those with estrogen, yet more frequent administration abolished any beneficial effects, (Table 2) [29].

We compared hip and heel BMD among nitrate users (391 women) and nonusers (5,827 women) identified by selfreport. Women who reported using ISMO, isosorbide dinitrate, or NTG more than once a day, every day, were classified as continuous users $(\mathrm{n}=317)$ and all other women were classified as intermittent users $(\mathrm{n}=74)$. Compared with nonusers, nitrate users were more likely to have risk factors for low BMD [27]. After adjusting for these differences, and for estrogen use, we found that hip BMD was 2.6\% higher and heel BMD was 5.3\% higher among intermittent nitrate users compared to nonusers and intermittent nitrate users had greater BMD than continuous users at both these sites (Table 3 ). The results were consistent with our hypothesis that intermittent use of nitrates improves bone mass while continuous nitrate use may lead to tachyphylaxis.

There are two potential explanations as to why intermittent nitrate use associated with greater BMD than continuous use. First, women who use nitrates intermittently may have better health and fewer risk factors for low BMD than women who require continuous nitrates. However, adjusting for known for differences in health status did not mitigate the nitrate effect. Second, the findings may be due to chance variation. However the results were robust and statistically significant when we examined BMD at both the hip and the heel.

The average dose of nitrate among women reporting intermittent use was $0.2 \mathrm{mg} /$ day of NTG. This is well below the doses required for angina treatment: a typical single dose is $0.3 \mathrm{mg}$ and daily doses range from $0.3 \mathrm{mg}$ to $0.9 \mathrm{mg}$. Among the 74 women reporting intermittent use, the type (ISMO, isosorbide dinitrate and NTG), the form (sublingual tablet or spray, oral tablets, sustained release tablets, transdermal patch or ointment), and the dose varied. This suggests an intriguing possibility that nitrates of any type 
Table 2: Percent change in lumbar spine BMD in ovariectomized rats after 12 weeks of treatment with nitroglycerin (NTG) ointment 29.

\begin{tabular}{lc}
\hline \multicolumn{1}{c}{ Treatment Group $(\mathrm{n}=5$ for all groups) } & Change in Lumbar Spine BMD \\
\hline Sham operated & $6.3 \% \pm 5.3 *$ \\
Ovariectomy (OVX) & $-2.5 \% \pm 2.0$ \\
OVX + estrogen & $5.9 \% \pm 3.4^{*}$ \\
OVX $+0.2 \mathrm{mg}$ nitroglycerin ointment once a day & $6.2 \% \pm 2.8^{*}$ \\
OVX $+0.2 \mathrm{mg}$ nitroglycerin ointment twice a day & $1.9 \% \pm 2.1$ \\
OVX +0.2 mg nitroglycerin ointment three times a day & $-0.2 \% \pm 3.3$ \\
\hline
\end{tabular}

administered intermittently in low doses can increase BMD.

The next step in our program of research was a RCT comparing the effects of placebo and intermittent ISMO on markers of bone turnover in postmenopausal women. We randomly assigned 144 women ( $\geq 3$ years postmenopausal with femoral neck BMD T-scores between 0 and -2.5) to 12 weeks of placebo or intermittent ISMO of $5 \mathrm{mg}$ or $20 \mathrm{mg}$ per day; typically ISMO is prescribed at $20 \mathrm{mg}$ twice a day. We measured changes from baseline in urine N-Telopeptide (NTx), a marker of bone resorption and serum Bone Specific Alkaline Phosphatase (BSAP), a marker of bone formation [30,31].

Our earlier work suggested that the effects of nitrates on bone was a class effect and as such we did not think the type of nitrate we chose would result in substantially different effects on markers of bone turnover [26]. We chose to study ISMO because it is completely and consistently absorbed, does not have a first pass effect, has linear dosedependent pharmacokinetics, and marked dose-dependent hemodynamic effects [32]. We chose doses of $5 \mathrm{mg}$ and $20 \mathrm{mg}$; pharmacologic data demonstrate that the threshold of oral activity of ISMO is $5 \mathrm{mg}$ and the maximum response is reached with doses of $20 \mathrm{mg}$ [33]. To prevent tachyphylaxis, we gave ISMO, which is typically administered twice a day, once a day or intermittently $[26,29]$.

We studied markers of bone turnover because substantial changes in markers can occur within 3 months of treatment $[34,35]$. As such, we were able to assess the potential utility of intermittent ISMO as a preventative agent for OP within a short time. Bone markers, particularly resorption markers, are considered reasonable surrogate end points for fractures [36-38]. A recent study demonstrated that the decrease in NTx observed after three to six months of risedronate therapy was significantly associated with the $75 \%$ reduction in vertebral fracture risk at one year and explained about half of the observed reduction in fracture risk [39]. The relationship between formation markers and fractures has not been extensively studied, but some studies suggest an increase in bone formation markers is associated with a decrease in subsequent fractures [40].

We found that, compared with placebo, women randomized to intermittent ISMO at $20 \mathrm{mg}$ had a $45.4 \%$ decrease in NTx (95\% confidence interval [CI]: 25.8 to 64.9 ) and a $23.3 \%$ increase (95\% CI: 8.9 to 37.8 ) in BSAP. Women randomized to intermittent ISMO at $5 \mathrm{mg}$ had a $36.3 \%$ decrease in NTx (95\% CI: 14.8 to 57.8 ) and a $15.9 \%$ increase in BSAP (95\% CI: 1.1 to 30.7) (Figure 2) $[30,31]$. The decreases in NTx observed with $20 \mathrm{mg}$ of

Table 3: Differences (mean \pm SD) in BMD at the total hip and heel in nitrate users and nonusers. Unadjusted and after adjusting for estrogen use and baseline differences (26).

\begin{tabular}{lll}
\hline & \multicolumn{1}{l}{ Percent difference in BMD $(95 \% \mathrm{Cl})$} & \\
\cline { 2 - 3 } & Daily-nonusers & Intermittent - nonusers \\
\hline Hip BMD & & \\
Unadjusted & $0(-2.7$ to I.4) & $0(-4.1$ to 4.1$)$ \\
Adjusted* & $1.3(0.14$ to 4.1$)$ & $2.6(0.4$ to 6.8$)$ \\
Heel BMD & & \\
Unadjusted & $-2.6(-5.3$ to 0$)$ & $0(-5.3$ to 7.9$)$ \\
Adjusted* & $0(-2.6$ to 2.6$)$ & $5.3(2.6$ to II)
\end{tabular}

*Adjusted for estrogen use and baseline differences (37), which are current alcohol intake, walks for exercise, physical activity, self-reported health status, falls in the past 12 months, thiazide and nonthiazide diuretic use, inability to rise from a chair independently and frail on physical examination. 


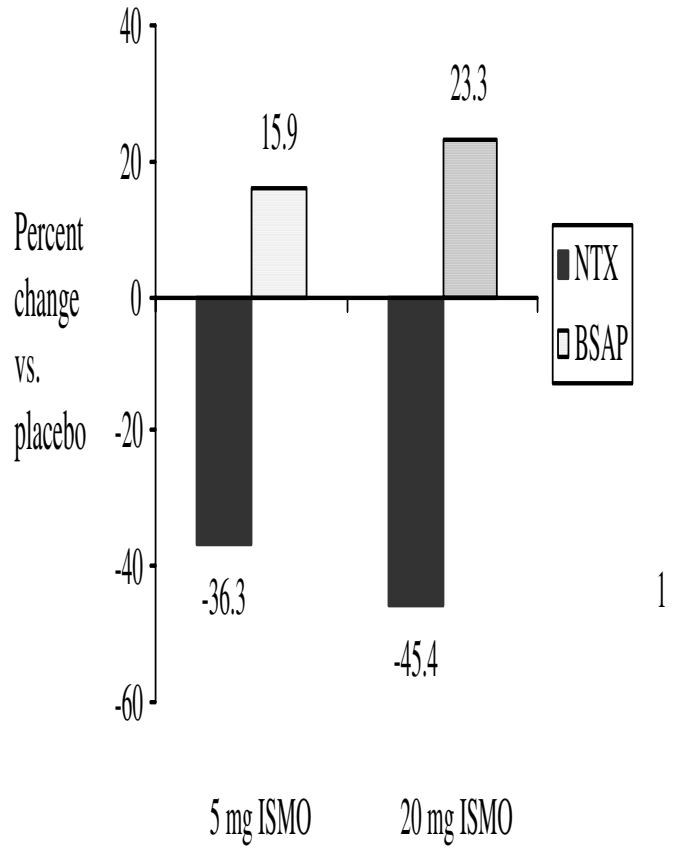

Figure 2

Percent change in urine NTx and serum BSAP in women randomly assigned to 5 or $20 \mathrm{mg}$ of ISMO daily compared with women assigned to placebo.

ISMO are similar to those reported with alendronate, risedronate, and estrogen (about 50\%) and greater than the $25 \%$ decreases reported with raloxifene $[40,41]$. However, all of the antiresorptive agents concomitantly decrease rates of bone formation. In contrast, we observed that treatment with ISMO resulted in significant increases in BSAP. The decrease in resorption, coupled with the increase in formation, suggests that ISMO may reduce fracture risk to an even greater degree than that seen with the current antiresorptive agents. The only adverse event was headache. Headaches, were more common among women randomized to ISMO ( 5 and $20 \mathrm{mg}$ groups combined $\mathrm{n}=55,57 \%)$ compared with placebo $(\mathrm{n}=2,4 \%$; $\mathrm{p}$ $=0.004)$. Headaches were no more common among women taking $20 \mathrm{mg}$ of ISMO $(\mathrm{n}=28)$ than among women taking $5 \mathrm{mg}$ of ISMO $(\mathrm{n}=27 ; \mathrm{p}=0.7)$.

Only one other study has examined the effects of nitrates on bone: an open label trial that randomized 16 oophorectomized women, aged 36 to 45 , to intermittent
NTG ointment (15 mg/day) or oral conjugated estrogen $(0.625 \mathrm{mg})$ [42]. After six months, women taking NTG ointment had a $40 \%$ decrease in NTx and 25\% increase in BSAP compared with baseline. This study, together with our findings, led U.S. investigators to design a 5 year RCT to study the effects of intermittent NTG ointment compared with placebo on lumbar spine BMD in 200 postmenopausal women. The trial is sponsored by the National Institute of Arthritis and Musculoskeletal and Skin Disease (NIAMS) and is currently recruiting subjects. The RCT we are conducting differs in many important ways from the NIAMS study (see section 2.1 below).

\subsection{Methods}

\section{I Study design}

This research proposal consists of two placebo controlled trials: a four week pilot study and a 27 month main study. The main study will be preceded by a one week nitrate run-in phase. Both the pilot and main study will recruit healthy postmenopausal women, 50 years of age and older, with lumbar spine BMD T scores between 0 and 2.0. The aim of the pilot study is to determine the best tolerated preparation of nitrate for future studies. We will assess eligibility for the pilot study by questionnaire, focused physical examination, electrocardiogram (ECG) and review of most recent BMD measurements. Subjects $(\mathrm{n}=22)$ will be randomly assigned to intermittent NTG at $15 \mathrm{mg} /$ day and intermittent ISMO at $20 \mathrm{mg} /$ day, each for one week. The order of the treatments will be random, accompanied by a placebo control (identical in sight and smell to the active treatment). In between each treatment there will be a two week washout period. Subjects will record the severity of headaches upon awakening every day for four weeks using a visual analog scale (VAS). We will calculate the mean headache score for each subject over both seven day treatment periods and then the mean headache score considering all subjects for each of the NTG and ISMO treatment periods.

The nitrate that is best tolerated will be used in our second, main study, whose primary objective is to assess the effects of intermittent nitrates on spine BMD (L1 to L4). To limit differential drop out due to headaches the main trial will follow from a one week nitrate run-in phase; women who discontinue the nitrate due to headaches will not enter the main trial. We will recruit 280 women and assess eligibility by questionnaire, focused physical examination, ECG, and BMD. We anticipate 17\% (48 of 280) of these subjects will be unable to tolerate nitrates due to headaches in the run-in phase, leaving 232 subjects for enrollment into the main study. At the start of the main study all subjects will undergo BMD testing on the same densitometer at the main study centre. We will also determine the total calcium and vitamin D intake, from diet and supplements, using a modified version of the Block 
Table 4A: Formula used for sample size calculation for pilot study.

$$
n=\left(Z_{I-\alpha / 2}+Z_{I-\beta}\right)^{2}\{I+(n-I) \rho\} /\left(n \Delta^{2}\right), \text { where } n=7, \rho=0.2, \Delta=\frac{25}{27.78}, \beta=0.1 \text {. }
$$

food frequency questionnaire. This 34-item questionnaire correlates well $(r=0.76)$ with the seven day food record and has been validated in postmenopausal women [4749]. Subjects will be given supplements as required so that all our subjects have an intake of $1500 \mathrm{mg} /$ day of calcium and $800 \mathrm{IU} /$ day of vitamin D. For the first 3 months after study entry, subjects will take only calcium and vitamin D supplements as required (pre-treatment phase). At 3 months, all subjects will have blood and urine samples taken for measurement of bone turnover markers, will undergo peripheral quantitative computed tomography (pQCT) assessments, and will be randomly assigned to placebo or active treatment, in addition to calcium and vitamin D. At 3, 12 and 24 months post randomization, subjects will return to the study centre and provide a fasting blood and second morning urine sample for bone turnover markers; the unused calcium, vitamin $\mathrm{D}$, and study medication will be counted and they will receive a new supply. We will measure BMD and pQCT 12 and 24 months post randomization. The design of the main study is summarized in Figure. 3.

An alternative design would be a single study on the effects of three treatments (placebo, NTG, ISMO) on $\mathrm{BMD}$, bone turnover markers, and pQCT. This design is inferior to our current approach for several reasons. Three treatment arms increases the number of subjects required, and increases recruitment time and study costs. Failure to identify the best tolerated nitrate prior to a larger, longer study may result in a large number of drop outs from adverse events that will reduce study efficiency and increase costs. Furthermore, 3 treatment arms necessitate the manufacturing and administration of both placebo paste and placebo pills, which increases study complexity and costs. Thus, we are well-justified in starting with a small short pilot study and then proceeding with the larger main trial. Three key features of this study that require further elaboration - the patient population, the rationale for the pilot study and nitrate run-in phase, and the outcomes measured - are discussed below.

\section{I.I Patient population: the rationale for studying postmenopausal women}

While we recognize that men are also at risk for OP, this RCT will include only postmenopausal women for several reasons. First, studies of nitrates to date have included only postmenopausal women. Second, after menopause in women and age 50 in men, men have higher estradiol levels than women and this difference may influence the effect of nitrates on bone [50]. A third issue is the rate of bone turnover; women, particularly in the first five years after menopause, have higher rates of bone turnover than men with OP [51-53]. These differences in bone turnover rates may lead to heterogeneity with respect to the BMD response to nitrates and may limit the power of our study. In particular, postmenopausal women randomized to placebo may have decreases in BMD while men may not.

\section{I.2 The pilot study and nitrate run-in phase}

No published studies compare nitrate preparations with respect to the frequency and severity of headaches. In our earlier study, 16 of the $96(17 \%)$ women randomized to ISMO dropped out due to headaches compared with 2 of $48(4 \%)$ women in the placebo $[30,31]$. All the women in the ISMO group who dropped out due to headaches did so within two days of randomization. The severity of the

Table 4B: Required sample size to test all secondary hypotheses in main study.

\begin{tabular}{llll}
\hline Hypothesis & Clinically Important Difference & Standard Deviation of Change & Subjects, per group \\
\hline $\begin{array}{l}\text { Hip BMD will be higher in } \\
\text { treatment group* }\end{array}$ & $2 \%$ & $4.5 \%(5,59,62,80,8 \mathrm{I})$ & 107 \\
$\begin{array}{l}\text { NTx will lower in treatment } \\
\text { groupt }\end{array}$ & $15 \%(69,87-89)$ & $28 \%(30,35)$ & 105 \\
$\begin{array}{l}\text { BSAP will be higher in treatment } \\
\text { groupt }\end{array}$ & $15 \%(69,87-89)$ & $25 \%(30)$ & 105 \\
$\begin{array}{l}\text { Headaches due to nitrates will be } \\
\text { higher in treatment group** }\end{array}$ & $20 \%(30)$ & $5 \%(30)$ & 36 \\
$\begin{array}{l}\text { Trabecular bone density by pQCT } \\
\text { will be higher in treatment group** }\end{array}$ & $10 \mathrm{mg} / \mathrm{cm}^{3}(67,70)$ & $7.5 \mathrm{mg} / \mathrm{cm}^{3}(67,70)$ & 31 \\
\hline
\end{tabular}

\footnotetext{
* Based on a t-test, assuming a two sided alpha of 0.05 a power of 0.90 and a standard deviation of change in BMD measurements of $4.5 \%$. † Assuming a repeated measures analysis of variance (75).

** Based on a Student's $t$ test, assuming a two sided alpha of 0.05 , a power of 0.90 .
} 


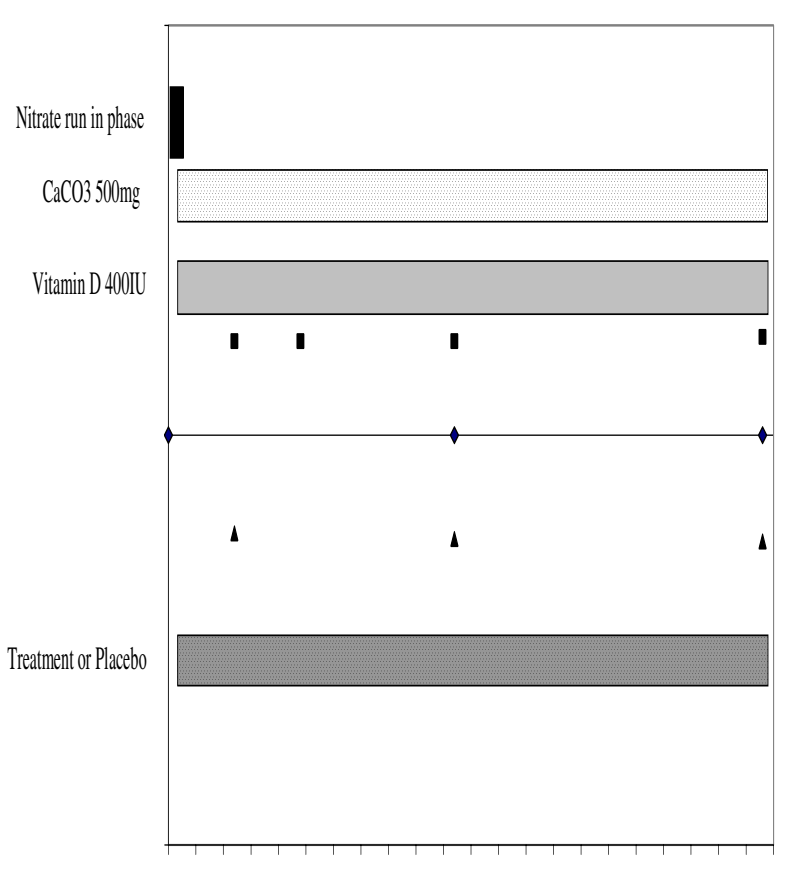

05101520253035404550556065707580859095100105110

\begin{tabular}{|c|}
\multicolumn{1}{c}{ Weeks } \\
\hline$\rightarrow$ BMD \\
\hline
\end{tabular}

\section{Figure 3}

Design of the main trial. *The main trial will be preceded by a one week nitrate run-in phase. Subjects who do not develop headaches during the run-in phase will then enter the main trial. The main trial consists of a 3 month pre-treatment phase with calcium and vitamin D. At 3 months subjects are randomized to treatment of placebo.

headaches determined drop out such that a woman with one day of severe headache was five times more likely to drop out than a woman with mild headaches for several days. Headaches were most severe upon awakening and subsided over the day. All headaches resolved within 24 hours of discontinuing the treatment assignment.

In the open label trial discussed earlier women were given $15 \mathrm{mg} /$ day of NTG ointment and no headaches were reported [42]. Although cross-trial comparisons are problematic, this difference suggests that NTG ointment is better tolerated than oral ISMO. One explanation relates to differences in pharmacokinetics; compared with NTG ointment, ISMO results in a much longer exposure to NO [54-57]. Alternative explanations relate to differences in subjects (the open label trial studied young women with surgical menopause who had hot flashes, while we stud- ied healthy older postmenopausal women), or in ascertainment of adverse events (the open label trial relied on self-report whereas we regularly inquired about headaches). Because there is considerable uncertainty about the relationship of nitrate preparation and headaches, our pilot study will focus on which of NTG or ISMO gives the least headaches.

To minimize differential drop out the main trial will be preceded by a one week nitrate run-in phase. All women eligible and willing to enter the trial will be instructed to take the nitrate, identified in the pilot as the best tolerated, for one week (as noted above women who develop headaches do so within 48 hours of taking the drug). Women who do not develop headaches will enter the main trial and, after 3 months of calcium and vitamin D (pre-treatment phase), will be randomized to placebo or treatment.

\section{I.3 The intervention: rationale for the nitrate preparation, dose, and frequency of administration}

Although several other forms of nitrates (e.g. transdermal patch, sublingual sprays) are available, we chose to study NTG ointment (15 mg/day) and oral ISMO (20 mg/day) because these are the only agents for which data on the safety and tolerability in healthy postmenopausal women exist. Moreover, the only studies that have reported changes in bone turnover markers have used either NTG ointment or ISMO. We will study the $20 \mathrm{mg}$ dose of ISMO as our earlier work found that this dose was associated with the greatest change in bone turnover markers $[30,31]$. There was no difference in headache incidence among women randomized to $5 \mathrm{mg}$ compared to $20 \mathrm{mg}$. The $20 \mathrm{mg}$ dose is marketed and readily available; this will be important if we use ISMO in a RCT of nitrates for fracture prevention.

We will study the $15 \mathrm{mg} /$ day dose of NTG ointment. This dose was used in the open label trial of NTG for the prevention of oophorectomy induced bone loss [42]. The 15 $\mathrm{mg} /$ day dose was based on dose response studies in rodents: a dose of $0.2 \mathrm{mg} / \mathrm{kg} /$ day of NTG was associated with the greatest change in bone turnover markers $[25,29,58]$.

We considered using the NTG patch instead of NTG ointment. The NTG patch has a major disadvantage: it has a long (24 hour) average duration of action and, therefore, may cause tachyphylaxis to the bone effects of nitrate. In contrast, the ointment has a much shorter ( 6 hour) average duration of action so that once daily administration avoids development of tachyphylaxis. We recognize that ointment is more difficult to apply than a transdermal patch and might stain clothing. However, we have used the ointment in 18 women in our pilot study with no mention by women of messiness or staining of clothes. 
Table 4C: Method for calculated percent change in BSAP and NTx

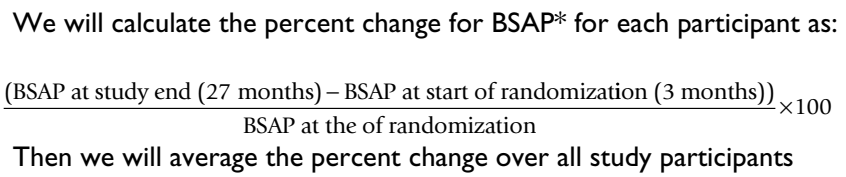

*We will perform identical calculations for NTx.

We will administer both NTG and ISMO once a day i.e. intermittently. While other dosing frequencies may increase BMD (e.g. continuous dosing, or even once weekly dosing), data from both the cardiovascular literature and our observational study suggest that too frequent dosing (e.g. ISMO $20 \mathrm{mg}$ twice a day or NTG every eight hours) is associated with tachyphylaxis while pharmacologic studies suggest that too infrequent dosing (e.g. less than once a day) results in increased frequency and severity of headaches. Thus, once daily or intermittent administration of nitrates will give the greatest change in BMD and the fewest headaches.

As noted earlier above only one other study (funded by NIAMS) is examining the effects of intermittent nitrates on bone in vivo. Our study differs from the NIAMS study in several important ways: 1 . We will determine which of NTG or ISMO is better tolerated in healthy postmenopausal women. This has never been done and is vital, both for the success of our proposal and for the potential clinical use of nitrates in future RCT's and clinical practice. 2. We will determine changes in bone turnover markers in response to nitrates, and 3 . We will evaluate changes in bone microarchitecture using PQCT. These latter two outcomes are not being assessed in the NIAMS study, yet turnover markers and microarchitecture contribute substantially to fracture risk $[9,62,69]$.

\subsection{Trial interventions}

\section{Pilot study}

Subjects will receive NTG ointment; at $15 \mathrm{mg} /$ day (one inch of $2 \%$ ointment applied to the upper arm) for one week and ISMO at $20 \mathrm{mg} /$ day for one week. The order of treatments will be randomized. In between each treatment there will be a two week washout. The washout exceeds ten half lives of NTG (one hour) and ISMO (five hours) and will eliminate any carryover effects [54-57]. Subjects who report headaches during the wash out will be excluded from the second treatment phase and considered as drop outs in our analysis. We have considered drop outs in our sample size calculations. Both treatments will be administered with placebo (tablet or paste, as appropriate). Subjects will receive standard instructions on how to take the tablet (at bed time with a glass of water; as was given in our earlier study) and patch (apply it first thing in the morning; as was given in the earlier study).

\section{Main study}

Subjects who are eligible and willing to participate in the main study will complete a standardized, validated, interviewer administered questionnaire designed to collect general demographics and evaluate factors that have been demonstrated in prospective observational studies to influence levels of bone turnover markers, BMD, and fracture risk [27]. The questionnaire will also assess total daily calcium and vitamin $\mathrm{D}$ intake using a modified version of the Block questionnaire. All subjects will be instructed to take the nitrate, identified in the pilot study to be the best tolerated, daily for one week. Subjects who do not develop headaches during the nitrate run-in phase will enter the main trial. The first 3 months of the main trial consist of a calcium and vitamin $\mathrm{D}$ pre-treatment phase. We will determine the total daily calcium and vitamin $D$ intake from questionnaire and we will provide calcium carbonate in $500 \mathrm{mg}$ tablets and vitamin D in $400 \mathrm{IU}$ tablets as needed so that the total daily calcium intake for all study subjects will be $1500 \mathrm{mg}$ and the vitamin D intake will be 800 IU; these are the intakes recommended in the recently published guidelines for the prevention and treatment of OP in Canada [70]. Calcium and vitamin D are the mainstay of all treatment regimens for OP and any new agent should be evaluated to assess the additional benefit it would provide. The three month calcium and vitamin $\mathrm{D}$ pre-treatment phase will limit any carryover effects of nitrates from the nitrate run-in phase. Further, by providing calcium and vitamin $\mathrm{D}$, we hope to discourage subjects who, after being enrolled in an "OP trial", start taking additional, unreported calcium and vitamin D (co-intervention). Calcium and vitamin $\mathrm{D}$ will be prepared and packaged by the study pharmacist, and instructions on how to take the supplements and the PI's office number will be printed on each bottle. Subjects will be given standard verbal instructions by the PI and reminded to take the calcium and vitamin D daily with the morning meal.

All subjects who return to the study centre at three months will undergo pQCT assessments, have blood and urine taken for measurement of bone turnover markers, and be randomly assigned to placebo or active treatment. Subjects will receive a 3 month supply of study medication, calcium, and vitamin $\mathrm{D}$, and will receive standard verbal and written instructions on how to take the medication, calcium, and vitamin D. At 3 months post randomization, 
subjects will return to the study centre and provide blood and urine samples for bone turnover markers; unused calcium, vitamin $\mathrm{D}$, and study medication will be collected and counted, and subjects will be given a nine month supply of study medication, calcium, and vitamin D. At 12 and 24 months post randomization, subjects will visit the study centre and provide blood and urine samples for bone turnover markers; the unused calcium, vitamin D and study medication will be counted (at the 12 month post randomization visit we will provide a 12 month supply of calcium, vitamin D and study medication) and we will obtain BMD and pQCT assessments (Figure. 3).

\subsection{Study subjects}

The pilot and main study have identical inclusion and exclusion criteria.

\section{Inclusion criteria}

1. Women aged 50 and older. 2. Lumbar spine BMD (L1 to L4) T score between 0 and -2.0 . 3. $\geq 3$ years postmenopausal.

\section{Exclusion criteria}

1. Prior low trauma hip or vertebral fracture; these subjects have OP and require treatment. 2. Total hip or femoral neck T score of $<-2.0$; these subjects either have OP and require treatment, or are at increased risk of developing OP over the course of the main study. 3. Bone disorders other than osteopenia (e.g. hyperparathyroidism or Paget's disease); these subjects require treatment. 4 . Treatment within six months of study entry with androgen, calcitonin, estrogen, progesterone, fluoride in a tablet form, raloxifene, tamoxifen, etidronate, prednisone or an equivalent at $5 \mathrm{mg} / \mathrm{d}$ for 12 months or greater, lithium or anticonvulsants. These agents can alter levels of bone turnover markers for up to six months. 5. Alendronate or risedronate use for at least four weeks, within the last three years. These agents may influence bone remodeling for up to three years. 6. Current treatment with nitrates. 7. Systolic blood pressure of $\leq 100 \mathrm{~mm} \mathrm{Hg}$ or diastolic blood pressure $\geq 110 \mathrm{~mm} \mathrm{Hg}$ at the baseline screening examination. 8. Abnormal ECG at the baseline screening examination. 9. History of myocardial infarction, angina, valvular or congenital heart disease. 10. Disabling conditions that may interfere with follow-up visits. 11 . Inability to give informed consent. 12. Migraine headaches; nitrates can exacerbate migraines. 13. Hypersensitivity to nitrates.

\subsection{Study outcomes}

\section{Pilot study}

The primary outcome will be mean headache score associated with each of intermittent NTG and ISMO use. Subjects will be given four seven day diaries, with a VAS for each day of both treatment periods and the wash out period. Subjects will rate their headache upon awakening on a daily basis; our previous study demonstrated that subjects randomized to ISMO who developed headaches reported that the headache was most severe upon awakening and gradually subsided over the day [43]. The VAS uses a $100 \mathrm{~mm}$ continuous horizontal line with the left pole labeled "no headache" and the right pole labeled "terrible headache"; subjects will be instructed to draw a vertical line intersecting the VAS indicating the severity of their morning headache. We will calculate the mean headache score with intermittent NTG and intermittent ISMO for each subject. Then we will calculate the mean headache score for all subjects when taking ISMO and when taking NTG. The nitrate that gives the lowest mean headache score will be used in our main study. Our earlier work indicates that the nitrate formulation associated with the most severe headaches will result in the greatest number of drop outs [30]. The VAS can detect subtle changes in subjective complaints (i.e. headache), has documented reliability, and has been used in several studies designed to study the effects of NTG ointment on headache in healthy women $[56,57]$.

\section{Main study}

The primary outcome will be the change from baseline in BMD at the lumbar spine over 24 months among women randomized to treatment compared with women randomized to placebo. BMD will be measured (on the same machine in all subjects) at the lumbar spine (L1 to L4) using a Lunar DPX-L bone densitometer (Lunar Corporation, Madison WI). A single experienced technician, certified by the International Society of Clinical Densitometry (ISCD) and blinded to the treatment assignment, will perform all BMD measurements. The intraclass correlation coefficient for BMD measurements is 0.98 [72]. The PI will be blinded to treatment assignment and will report the $\mathrm{BMD}$. BMD reporting is objective and based on standard ISCD criteria.

We will assess four secondary outcomes in the main study:

\section{Change from baseline in total hip BMD}

This will provide information about the effects of nitrates on cortical and trabecular bone and ultimately on the ability of nitrates to prevent hip fractures.

\section{Change from baseline in bone formation and bone resorption markers}

Measuring markers of bone turnover will increase our understanding of the mechanisms by which intermittent nitrates increase BMD (i.e. a decrease in bone resorption and/or an increase in bone formation). We will measure bone turnover markers three months after initiating calcium and vitamin D because we expect a $10 \%$ decrease in markers with the use of supplements, and the maximal change in bone markers is typically observed at three 
months [36]. Thus, we will be assessing any additional effects of intermittent nitrates on markers of bone turnover in women receiving calcium and vitamin D supplements. Urinary NTx will be measured on a second morning urine sample using a monoclonal antibody technique (Osteomark) [73]. The intra-assay variability is $7.6 \%$ and the inter-assay variability is $4.0 \%$. Serum BSAP will be measured on a fasting serum sample using a monoclonal antibody technique (Metra Biosystems) [74]. The intra-assay variability is $5.8 \%$ and the inter-assay variability is $5.2 \%$. To minimize variability, subjects will be given written and verbal instructions on how to collect the second morning urine sample; for each subject we will collect all the samples (baseline, three, 12 and 24 month post randomization) at the same time, and we will store the blood and urine at $-70^{\circ} \mathrm{C}$ and analyze all the samples together in a single laboratory. We will compare measures of bone turnover markers at 3, 12, and 24 months after randomization using a repeated measure of analysis of variance [75]. By measuring markers at three months we will be able to directly compare these results to the findings in our earlier study. By measuring markers at 12 and 24 months we will be able to evaluate to a limited degree, the question of tachyphylaxis with nitrates. Recall that in our earlier study we found a decrease in markers of bone resorption and an increase in markers of bone formation after 90 days of treatment with intermittent ISMO [30,31]. Measuring markers after one and two years of treatment will allow us to determine if there is still a marked decrease in bone resorption and increase in bone formation; no further changes in markers may indicate that the effects of nitrates on bone is transient.

\section{Adverse events}

Adverse events will be assessed using a standardized, validated interviewer administered questionnaire on a monthly basis by telephone.

\section{Bone microarchitecture}

Fracture risk is influenced by both the quantity of bone (assessed by BMD) and quality of bone. Fracture risk is influenced by both the quantity of bone (assessed by $\mathrm{BMD}$ ) and quality of bone. Indeed, recent reports suggest that up to $40 \%$ of fracture risk is explained by decreases in bone quality $[5,62]$. Our results indicate that nitrates increase bone formation. Exercise and agents, such as $\mathrm{PTH}$, that form bone add bone to the periosteal surface of cortical bone; this may also apply to nitrates. Small increases in the external diameter of bone substantially increase the bending strength of long bones. Unfortunately, bone density by DXA of the complex structures of hip and spine have poor resolution of cortical bone edges and cannot accurately measure the periosteal accretion of cortical bone. In fact, addition of periosteal bone will increase the diameter and, therefore, the projected area of a bone. Since BMD is calculated as total bone mineral content divided by bone area, an increase in bone diameter may paradoxically tend to decrease BMD! Therefore, it is essential to use a measurement that precisely measures cortical dimensions in tubular bone.

Cross-sectional moment of inertia is one of the best biomechanical measurements of the strength of long bones. Trabecular density also contributes to the strength of many bones with high trabecular content. All of these features can be measured with pQCT [66]. PQCT measures are precise, with a minimum detectable change for volumetric bone density of $0.03 \mathrm{~g} \mathrm{~cm}^{-3}[67,68]$. PQCT measurements of volumetric bone density and trabecular bone texture have been used by researchers at McMaster University to demonstrate that reductions in fracture risk induced by hormone replacement therapy are due to deposition of bone at the endocortical surface [67]. Statistically significant responses in density, area and texture were detected within six months when 21 women starting therapy were compared with 32 matched controls. Previous work at McMaster was performed with a second generation PQCT machine. The investigators at McMaster have recently obtained a third generation scanner (Stratec XCT2000) that allows measurements of greater reproducibility in both the radius (nonweight bearing) and the tibia (weight bearing). This is particularly relevant with regard to NO as in vitro studies demonstrate that the nitric oxide synthase gene promoter is activated in response to shear stress (equivalent to weight bearing in humans) [68]. Thus, increased levels of NO that results in decreased bone resorption may be one mechanism by which weight bearing prevents bone loss. Our study will test this hypothesis by comparing $\mathrm{PQCT}$ measurements in the radius (nonweight bearing) and tibia (weight bearing) among women randomized to nitrates and placebo.

\subsection{Sample size}

Pilot study

We wish to detect at least 15 units difference in headache score using the VAS between the intermittent NTG and ISMO groups, which is consistent with a modest effect [57]. We assumed a power of $90 \%$ and two sided alpha of 0.05 , a standard deviation of 27.78 (based on studies using the VAS to report headaches in healthy women), $[56,57]$ and a small correlation of 0.5 among the repeated measurements [77]. Based on these assumptions, the number of subjects needed for comparing (paired) the mean headache scores for two groups is 20 subjects (Table $4 \mathrm{~A})$. We will increase this number by $10 \%$, to account for women who develop headaches that continue into the washout period and cannot go on to the second treatment. Note that this is a conservative approach, in our earlier study all women who developed headaches reported that when they stopped the treatment the headache 
resolved within 24 hours. Based on these assumptions, we will require 22 subjects for our pilot study.

\section{Main study}

Our primary hypothesis is that, after 27 months, we will observe a clinically important and statistically significant increase in lumbar spine $\mathrm{BMD}$, expressed in percent change from baseline, among women randomized to treatment compared with placebo. Our sample size calculation is based on t-test and will allow us to detect a $2 \%$ difference in spine $\mathrm{BMD} ; 2 \%$ is the minimal difference that would justify nitrate treatment as this is the minimal magnitude of BMD change observed with other accepted osteoporosis treatments $[5,61,62,78,79]$. The standard deviation of change with a $2 \%$ difference in BMD ranges from $4.5 \%$ to $6.8 \%[5,59,62,80,81]$. Assuming a standard deviation of change of $4.5 \%$, a two sided alpha of 0.05 and a power of 0.90 we require 107 subjects per group [81].

The main trial will be preceded by a nitrate run-in phase and only women who complete the run-in phase will be entered into the main trial (see section 2.1aii). Our previous data indicate that 16 of $96(17 \%)$ women randomized to ISMO dropped out due to headaches and 6 of the 144 (4\%) women did not return to the study centre after randomization and were lost to follow up [42]. Thus we will "over recruit" by $25 \%$ to allow for a $17 \%$ drop out in the run-in phase due to headaches and a $8 \%$ loss to follow up during the main trial. Thus, we will recruit 280 subjects of whom we anticipate that 232 subjects will complete the run-in phase and enter the main trial (116 subjects per group). This sample size will ensure that we observe a clinically important and statistically significant difference between the active treatment and placebo group. Our sample size gives us adequate power to test our secondary hypotheses (Table 4B).

The estimated $17 \%$ drop out rate from headaches in the run-in phase is conservative as the pilot study will identify the best tolerated nitrate. We anticipate that less than $1 \%$ of women will drop out from headaches during our main trial based on the fact that in our earlier trial the majority of the women who dropped out due to headaches did so within the first 48 hours.

\subsection{Data analysis}

Our main analysis will be intention to treat [86]. There will be no subgroup or interim analysis.

\section{Pilot study}

We will use a paired t test to examine for differences in headache score when subjects are randomized to intermittent ISMO compared to the same subjects randomized to intermittent NTG.

\section{Main study}

For all of the outcomes in our main study we will compare differences, at 27 months, between the intermittent nitrate group and the placebo group. To determine the percent change in total lumbar spine and hip BMD we will use a Student's t test. We will aim to have follow-up measurements on $100 \%$ of subjects randomized and plan to do an intention to treat analysis including measurements. To determine the percent change in BSAP and NTx we will use a repeated measures analysis of variance, after calculating the percent change in BSAP and NTx for each subject (see Table 4C). To determine if the incidence of headaches is higher in the intermittent nitrate group compared to the placebo group we will use a Student's t test. We will also use a Student's t test to determine if trabecular density by pQCT is higher in the intermittent nitrate group compared to the placebo group (Table 4B).

\subsection{Trial management}

This is be a multicentre trial that will recruit from five sites: The University Health Network, St. Michael's Hospital, Women's College Ambulatory Care Centre, Sunnybrook Health Sciences Centre, and the Hamilton Health Sciences Centre at McMaster University. As well, we will confer with national and international experts on the conduct of the trial and the interpretation of our data.

All adverse events and significant medical conditions will be recorded and faxed to the committee for adjudication. Subjects will be discontinued from the study if they develop clinical fractures, if their BMD falls below -2.5 at one-year, or if they develop medical conditions that necessitate starting nitrates (e.g. developing angina).

\subsection{Discussion}

We successfully completed our pilot study in August 2005. We found that headaches were significantly lower when women were randomized to nitroglycerin ointment compared with oral isosorbide mononitrate. As a result, the main study is assessing the effects of nitroglycerin ointment on bone mineral density. To date, we have screened 310 subjects, 77 have entered the one week nitrate run in phase, 25 women dropped out after the one week nitrate run-in phase (19 of these due to headaches) have dropped out and 52 women are still participating in the trial.

Nitrates have several advantages over the medications currently used to prevent and treat OP. Unlike ERT, there have been no reports of an increased risk of cardiovascular disease or breast cancer with long-term use of nitrates [4346]. Compared with bisphosphonates and raloxifene, nitrates are generally more available world wide, more convenient to take, and less expensive. Clearly, further studies of nitrates are essential. 
The value of nitrates for prevention of fracture will require a randomized blinded trial with a fracture outcome. We plan to conduct an international trial comparing intermittent nitrates with standard pharmacologic therapy to prevent fractures in women with OP. Prior to the RCT, we must determine the form of nitrate that is associated with the least severe headaches and also determine if intermittent nitrates can increase spine BMD. These are the main objectives of this trial.

\section{Competing interests}

The author(s) declare that they have no competing interests.

\section{Authors' contributions}

All 4 authors have made substantial contributions to the study conception and design, acquisition of data and analysis and interpretation of data. Each author has been intimately involved in drafting and editing the manuscript and approves the final version for publishing.

\section{Acknowledgements}

This study has been funded by the following parties:

Physicians' Services Incorporated Foundation (PSI)

Canadian Institutes of Health Research (CIHR)

Dr. Sophie A. Jamal is funded by a CIHR New Investigator's Award.

\section{References}

I. Hawker G: Chapter I: Epidemiology of Arthritis and Osteoporosis. In Patterns of Health Care in Ontario: Arthritis and Related Conditions Edited by: Bradley EM, Williams JI. Toronto: Institute of Clinical Evaluative Sciences; 1998.

2. Jaglal S: Chapter 8: Osteoporotic Fractures: Incidence and Impact. In Patterns of health care in Ontario. Arthritis and related conditions Edited by: Bradley EM, Williams JI. Toronto: Continental Press; 1998.

3. Melton LJl, Cooper C: Magnitude and impact of osteoporosis and fractures. In Osteoporosis 2 nd edition. Edited by: Marcus R, Feldman D, Kelsey J. San Diego: Academic Press; 200I:557-567.

4. Gullberg B, Johnell O, Kanis JA: World-wide projections for hip fracture. Osteoporos Int 1997, 7(5):407-4I3.

5. Cummings SR, Palermo L, Browner W, Marcus R, Wallace R, Pearson J, Blackwell T, Eckert S, Black D: Monitoring osteoporosis therapy with bone densitometry: misleading changes and regression to the mean. Fracture Intervention Trial Research Group. JAMA 2000, 8:1318-1321.

6. Cryer R, Bauer DC: Oral bisphosphonates and upper gastrointestinal tract problems: what is the evidence? Mayo Clin Proc 2002, 77(10): 1031-1043.

7. Bauer DC, Black D, Ensrud K, Thompson D, Hochberg M, Nevitt M, Musliner T, Freedholm D: Upper gastrointestinal tract safety profile of alendronate: the fracture intervention trial. Arch Intern Med 2000, 160(4):517-525.

8. Risks and benefits of estrogen plus progestin in healthy postmenopausal women: principal results From the Women's Health Initiative randomized controlled trial. JAMA 2002, 288(3):32I-333.

9. Cummings SR, Cosman F, Jamal SA, editors: Osteoporosis. An evidenced-based guide to prevention and management. Philadelphia: American College of Physicians; 2002.

10. Cummings SR, Eckert S, Krueger KA, Grady D, Powles TJ, Cauley JA, Norton L, Nickelsen T, Bjarnason NH, Morrow M, Lippman ME, Black $D$, Glusman JE, Costa A, Jordan VC: The effect of raloxifene on risk of breast cancer in postmenopausal women: results from the MORE randomized trial. Multiple Outcomes of Raloxifene Evaluation. JAMA 1999, 28 I (23):2।89-2I97.

II. Chae HJ, Park RK, Chung HT, Kang JS, Kim MS, Choi DY, Bang BG, Kim HR: Nitric oxide is a regulator of bone remodelling. J Pharm Pharmacol 1997, 49(9):897-902.

12. Evans DM, Ralston SH: Nitric oxide and bone. J Bone Miner Res 1996, II(3):300-305.

13. Evans $\mathrm{CH}$, Stefanovic-Racic M, Lancaster J: Nitric oxide and its role in orthopaedic disease. Clin Orthop 1995:275-294.

14. Feelisch M: Biotransformation to nitric oxide of organic nitrates in comparison to other nitrovasodilators. European Heart Journal 1993, 14:123-132.

15. Maclntyre I, Zaidi M, Alam AS, Datta HK, Moonga BS, Lidbury PS, Hecker M, Vane JR: Osteoclastic inhibition: an action of nitric oxide not mediated by cyclic GMP. Proc Natl Acad Sci USA 199I, 88(7):2936-2940.

16. Lowik CW, Nibbering PH, van de Ruit M, Papapoulos SE: Inducible production of nitric oxide in osteoblast-like cells and in fetal mouse bone explants is associated with suppression of osteoclastic bone resorption. J Clin Invest 1994, 93(4): | 465- 1472.

17. Collin-Osdoby P, Nickols GA, Osdoby P: Bone cell function, regulation and communication: a role for nitric oxide. Journal of Cellular Biochemistry 1995, 57:399-408.

18. Ralston SH: The Michael Mason Prize Essay 1997. Nitric oxide and bone: what a gas! Br J Rheumatol 1997, 36(8):83I-838.

19. Ralston SH, Ho LP, Helfrich MH, Grabowski PS, Johnston PW, Benjamin N: Nitric oxide: a cytokine-induced regulator of bone resorption. J Bone Miner Res 1995, I 0(7): 1040-1049.

20. Brandi ML, Hukkanen M, Umeda T, Moradi-Bidhendi N, Bianchi S, Gross SS, Polak JM, Maclntyre I: Bidirectional regulation of osteoclast function by nitric oxide synthase isoforms. Proceedings of the National Academy of Sciences USA 1995, 92:2954-2958.

21. Kasten TP, Collin-Osdoby P, Patel N, Osdoby P, Krukowski M, Misko TP, Settle SL, Currie MG, Nickols GA: Potentiation of osteoclast bone-resorption activity by inhibition of nitric oxide synthase. Proc Natl Acad Sci USA 1994, 9 I (9):3569-3573.

22. Chow JW, Fox SW, Lean JM, Chambers TJ: Role of nitric oxide and prostaglandins in mechanically induced bone formation. J Bone Miner Res 1998, 13(6):1039-1044.

23. van't Hof RJ, Ralston SH: Cytokine-induced nitric oxide inhibits bone resorption by inducing apoptosis of osteoclast progenitors and suppressing osteoclast activity. J Bone Miner Res 1997, I 2(II): 1797-I804.

24. Ake Y, Saegusa Y, Matsubara T, Mizuno K: Cultured osteoblast synthesize nitric oxide in response to cytokines and lipopolysaccharide. Kobe J Med Sci 1994, 40(3-4): I25-137.

25. Wimalawansa SJ, De Marco G, Gangula P, Yallampalli C: Nitric oxide donor alleviates ovariectomy-induced bone loss. Bone 1996, I8(4):30I-304.

26. Jamal SA, Browner WS, Bauer DC, Cummings SR: Intermittent use of nitrates increases bone mineral density: the study of osteoporotic fractures. J Bone Miner Res 1998, I3(I I): 1755-I759.

27. Cummings SR, Nevitt MC, Browner WS, Stone K, Fox KM, Ensrud $\mathrm{KE}$, Cauley J, Black D, Vogt TM: Risk factors for hip fracture in white women. Study of Osteoporotic Fractures Research Group. N Engl J Med 1995, 332(12):767-773.

28. Thadani U: Nitrate tolerance, rebound, and their clinical relevance in stable angina pectoris, unstable angina, and heart failure. Cardiovascular Drugs and Therapy 1997, 10:734-742.

29. Wimalawansa SJ, Chapa T, Wimalawansa S, Fang L, Yallampalli C: Dose and frequency effects of nitric oxide donor nitroglycerine on bone. Seventy - ninth Annual Meeting of the Endocrine Society, Minneapolis, USA 1997. (abst P3-248)

30. Jamal SA: The effects of isosorbide mononitrate on markers of bone turnover: a randomized double blind placebo controlled trial [PhD]. Toronto: University of Toronto; 2003.

31. Jamal SA, Cummings SR, Hawker GA: The effects of isosorbide mononitrate on bone turnover: A randomized controlled trial. J Bone Miner Res 2004, 19(9): I5 I 2-1517.

32. Fung $\mathrm{H}$ : Pharmacokinetics of nitroglycerin and long-acting nitrate esters. Am J Med I983, I 2:13-20.

33. Abshagen A, Sporl-Radun S: First data on effects and pharmacokinetics of isosorbide-5-mononitrate in normal man. Eur J Clin Pharmacol 1981, 19:423-429. 
34. Hannon R, Eastell R: Preanalytical variability of biochemical markers of bone turnover. Osteoporos Int 2000, I I(Suppl 6): $S 30-S 44$.

35. Hannon R, Blumsohn A, Naylor K, Eastell R: Response of biochemical markers of bone turnover to hormone replacement therapy: impact of biological variability. J Bone Miner Res 1998, 13:1 I24-1133.

36. Eastell R, Blumsohn A: The value of biochemical markers of bone turnover in osteoporosis. J Rheumatol 1997, 24:1215-1217.

37. Fleming TR, DeMets DL: Surrogate end points in clinical trials: are we being misled? Ann Intern Med 1996, 1 25(7):605-6I3.

38. Clowes JA, Eastell R: The role of bone turnover markers and risk factors in the assessment of osteoporosis and fracture risk. Baillieres Best Pract Res Clin Endocrinol Metab 2000, I 4(2):213-232.

39. Eastell R, Barton I, Hannon RA, Chines A, Garnero P, Delmas PD: Relationship of early changes in bone resorption to the reduction in fracture risk with risedronate. J Bone Miner Res 2003, I 8: 105I-1056.

40. Hochberg MC, Greenspan S, Wasnich RD, Miller P, Thompson DE, Ross PD: Changes in bone density and turnover explain the reductions in incidence of nonvertebral fractures that occur during treatment with antiresorptive agents. J Clin Endocrino Metab 2002, 87(4): I586-1592.

41. Looker AC, Bauer DC, Chesnut CH 3rd, Gundberg CM, Hochberg MC, Klee G, Kleerekoper M, Watts NB, Bell NH: Clinical use of biochemical markers of bone remodeling: current status and future directions. Osteoporos Int 2000, I I (6):467-480.

42. Wimalawansa SJ: Nitroglycerin therapy is as efficacious as standard estrogen replacement therapy (Premarin) in prevention of oophorectomy-induced bone loss: a human pilot clinical study. J Bone Miner Res 2000, I 5( I I):2240-2244.

43. Thadani $U$, Lipicky RJ: Ointments and transdermal nitroglycerin patches for stable angina pectoris. Cardiovasc Drugs Ther 1994, 8(4):625-633.

44. Thadani U, Lipicky RJ: Short and long-acting oral nitrates for stable angina pectoris. Cardiovasc Drugs Ther 1994, 8(4):6 I I-623.

45. Thadani U, Opie LH: Nitrates for unstable angina. Cardiovasc Drugs Ther 1994, 8(5):719-726.

46. Asirvatham S, Sebastian $\mathrm{C}$, Thadani U: Choosing the most appropriate treatment for stable angina. Safety considerations. Drug Saf 1998, 19(I):23-44

47. Block G, Hartman AM, Naughton D: A reduced dietary questionnaire: development and validation. Epidemiol 1990, 1:58-64.

48. Cumming RG, Nevitt MC: Calcium for prevention of osteoporotic fractures in postmenopausal women. J Bone Miner Res 1997, I 2(9): I321-1329.

49. Cummings SR, Block G, McHenry K, Baron RB: Evaluation of two food frequency methods of measuring calcium intake. $\mathrm{Am} J$ Epidemiol 1987, 1 26:796-802.

50. Riggs BL, Khosla S, Melton LJ: Sex steroids and the construction and conservation of the adult skeleton. Endocrine Reviews 2002 23:279-302.

51. Nilas L, Christiansen CC: Rates of bone loss in normal women: evidence of accelerated trabecular bone loss after the menopause. Eur J Clin Invest 1988, I 8:529-534.

52. Orwoll ES, Oviatt SK, McClung MR, Deftos LJ, Sexton G: The rate of bone mineral loss in normal men and the effects of calcium and cholecalciferol supplementation. Ann Intern Med 1990, I I 2:29-34.

53. Recker RR, Lappe J, Davies K, Heaney R: Characterization of perimenopausal bone loss: a prospective study. J Bone Miner Res 2000, I5:1965-1973.

54. Christiansen I, Iversen HK, Olesen J: Headache characteristics during the development of tolerance to nitrates: pathophysiologic implications. Cephalagia 2000, 20:437-444.

55. Bogaert MG: Pharmacokinetics of organic nitrates in man: an overview. European Heart Journal 1988, 9(Supplement A):33-37.

56. Shively M, Riegel B: Effect of nitroglycerin ointment placement on headache and flushing in healthy subjects. Int J Nurs Stud 1991, 28:153-161.

57. Riegel B, Heywood G, Jackson W, Kennedy A: Effect of nitroglycerin ointment placement on the severity of headache and flushing in patients with cardiac disease. Heart Lung 1988 17:426-431.
58. Wimalawansa SJ, Chapa MT, Yallampalli C, Zhang R, Simmons DJ: Prevention of corticosteroid-induced bone loss with nitric oxide donor nitroglycerin in male rats. Bone 1997, 2 I (3):275-280.

59. Bates DW, Black DM, Cummings SR: Clinical use of bone densitometry: clinical applications. JAMA 2002, 288(I 5): | 898-1900.

60. Cummings SR, Kelsey JL, Nevitt MC, O'Dowd KJ: Epidemiology of osteoporosis and osteoporotic fracture. Epidemiol Rev 1985, 7:178-208.

61. Cummings SR, Black D: Bone mass measurements and risk of fracture in Caucasian women: a review of findings from prospective studies. Am J Med 1995, 98(2A):24S-28S.

62. Cummings SR, Bates D, Black DM: Clinical use of bone densitometry: scientific review. JAMA 2002, 288(15): I889-1897.

63. Dargent-Molina P, Favier F, Grandjean H, Baudoin C, Schott AM, Hausherr E, Meunier PJ, Breart G: Fall-related factors and risk of hip fracture: the EPIDOS prospective study. Lancet 1996, 348: I 45-I 49.

64. Heaney RP, Abrams S, Dawson-Hughes B, Looker A, Marcus R, Matkovic V, et al:: Peak bone mass. Osteoporos Int 2000, II(I 2):985-1009.

65. Marcus R: Post-menopausal osteoporosis. Best Pract Res Clin Obstet Gynaecol 2002, 16(3):309-327.

66. Gordon CL, Webber CE, Adachi JD, Christoforou N: In vivo assessment of trabecular bone structure at the distal radius from high resolution computed tomography images. Physics in Medicine and Biology 1996, 41:495-508.

67. Muller ME, Webber CE, Adachi JD: Hormone replacement therapy improves distal radius bone structure by endocortical mineral deposition. Can J Phyisol Pharmacol 2003, 81:952-958.

68. Klein-Nulend J, Helfrich MH, Sterck JG, MacPherson H, Joldersma M, Ralston SH, et al.: Nitric oxide response to shear stress by human bone cell cultures is endothelial nitric oxide synthase dependent. Biochem Biophys Res Commun 1998, 250( I): I08-I I4.

69. Cummings SR, Melton J: Epidemiology and outcomes of osteoporotic fractures. Lancet 2002, 359:1761-1767.

70. Brown JP, Josse RG: 2002 clinical practice guidelines for the diagnosis and management of osteoporosis in Canada. CMAJ 2002, I67( 10 Suppl):SI-S34.

7I. Wallin J, Sjovall J: Detection of adverse drug reactions in a clinical trial using two types of questioning. Clin Ther 1981, 3:450-452.

72. Genant HK, Engelke K, Fuerst T, Gluer CC, Grampp S, Harris ST, Jergas M, Lang T, Lu Y, Majumdar S, Mathur A, Takada M: Noninvasive assessment of bone mineral and structure: state of the art. Bone Miner Res 1996, I I(6):707-730.

73. Osteomark NTx Urine Product Description. Seattle: Ostex International Inc; 2002.

74. Metra BAP EIA kit. San Diego: Quidel Corporation; 2002. Report No.: 8012 .

75. Glantz SA: Primer of Biostatistics Fourth edition. New York: McGrawHill; 1997.

76. Maclntyre NJ, Adachi JD, Webber CE: In vivo measurement of apparent trabecular bone structure of the radius in women with low bone density discriminates patients with recent wrist fracture from those without fracture. Journal of Clinical Densitometry 2003, 6:35-43.

77. Diggle PJ, Liang KY, SL Z: Analysis of Longitudinal Data: Oxford Science Publications; 1994.

78. Cummings SR, Black DM, Thompson DE, Applegate WB, BarrettConnor E, Musliner TA, Palermo L, Prineas R, Rubin SM, Scott JC, Vogt T, Wallace R, Yates AJ, LaCroix AZ: Effect of alendronate on risk of fracture in women with low bone density but without vertebral fractures: results from the Fracture Intervention Trial. JAMA 1998, 280(24):2077-2082.

79. Black DM, Greenspan SL, Ensrud KE, Palermo L, McGowan JA, Lang TF, Garnero P, Bouxsein ML, Bilezikian JP, Rosen CJ, PaTH Study Investigators: The effects of parathyroid hormone and alendronate alone or in combination postmenopausal osteoporosis. N Engl J Med 2003, 349:1207-12I5.

80. Ettinger B, Black DM, Mitlak BH, Knickerbocker RK, Nickelsen T, Genant HK, Christiansen C, Delmas PD, Zanchetta JR, Stakkestad J, Gluer CC, Krueger K, Cohen FJ, Eckert S, Ensrud KE, Avioli LV, Lips $P$, Cummings SR: Reduction of vertebral fracture risk in postmenopausal women with osteoporosis treated with raloxifene: results from a 3-year randomized clinical trial. 
Multiple Outcomes of Raloxifene Evaluation (MORE) Investigators. JAMA 1999, 282(7):637-645.

81. Black DM, Reiss TF, Nevitt MC, Cauley J, Karpf D, Cummings SR: Design of the Fracture Intervention Trial. Osteoporos Int 1993 3(Supl 3):S29-S39.

82. Johnell O, Kanis JA, Black DM, Balogh A, Poor G, Sarkar S, Zhou C, Pavo I: Associations between baseline risk factors and vertebral fracture risk in the Multiple Outcomes of Raloxifene Evaluation (MORE) Study. J Bone Miner Res 2004, 19:764-772.

83. Varosy PD, Shlipak MG, Vitttinghoff E, Black DM, Herrington D, Hulley SB, Browner WS: Heart and Estrogen/Progestin Replacement Study(HERS) Investigators: Fracture and the risk of coronary events in women with heart disease. Am J Med 2003, I I 5:196-202.

84. Haas JS, Kaplan CP, Gerstenberger EP, Kerlikowske K: Changes in the use of postmenopausal hormone therapy after the publication of clinical trial results. Ann Intern Med 2004, I 40: $184-188$.

85. Choo PW, Rand CS, Inui TS, Lee ML, Cain E, Cordeiro-Breault M, Canning C, Platt R: Validation of patient reports, automated pharmacy records, and pill counts with electronic monitoring of adherence to antihypertensive therapy. Med Care 1999 37(9):846-857.

86. Lewis JA, Machin D: Intention to treat - who should use ITT? $\mathrm{Br}$ J Cancer 1993, 68(4):647-650.

87. Clowes JA, Eastell R: Markers of bone turnover and laboratory evaluation of secondary osteoporosis. In Osteoporosis: an evidenced-based guide to prevention and management Edited by: Cummings SR, Cosman F, Jamal SA. Philadelphia: American College of Physicians; 2002:59-82.

88. Delmas PD: Markers of bone turnover for monitoring treatment of osteoporosis with antiresorptive drugs. Osteoporos Int 2000, I I(Suppl 6):S66-S76.

89. Delmas PD, Eastell R, Garnero P, Seibel MJ, Stepan J: The use of biochemical markers of bone turnover in osteoporosis. Committee of Scientific Advisors of the International Osteoporosis Foundation. Osteoporos Int 2000, II(Suppl 6):S2-SI7.

Publish with Bio Med Central and every scientist can read your work free of charge

"BioMed Central will be the most significant development for disseminating the results of biomedical research in our lifetime. "

Sir Paul Nurse, Cancer Research UK

Your research papers will be:

- available free of charge to the entire biomedical community

- peer reviewed and published immediately upon acceptance

- cited in PubMed and archived on PubMed Central

- yours - you keep the copyright 